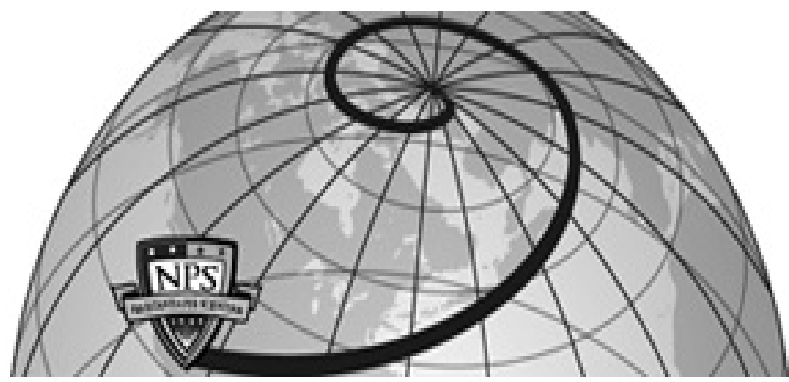

Calhoun: The NPS Institutional Archive DSpace Repository

\title{
A Theory for the Tropical Tropospheric Biennial Oscillation
}

Chang, C.-P.; Li, Tim

Journal of the Atmospheric Sciences, Vol. 57, No. 14, 15 July 2000, pp. 2209-2224 https://hdl.handle.net/10945/40142

This publication is a work of the U.S. Government as defined in Title 17, United States Code, Section 101. Copyright protection is not available for this work in the United States.

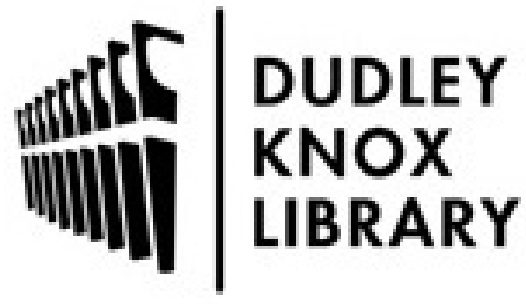

http://www.nps.edu/library
Calhoun is the Naval Postgraduate School's public access digital repository for research materials and institutional publications created by the NPS community. Calhoun is named for Professor of Mathematics Guy K. Calhoun, NPS's first appointed -- and published -- scholarly author.

\section{Dudley Knox Library / Naval Postgraduate School} 411 Dyer Road / 1 University Circle Monterey, California USA 93943 


\title{
A Theory for the Tropical Tropospheric Biennial Oscillation
}

\author{
C.-P. Chang AND Tim Li \\ Department of Meteorology, Naval Postgraduate School, Monterey, California
}

(Manuscript received 11 August 1998, in final form 30 August 1999)

\begin{abstract}
The key questions of how the tropospheric biennial oscillation (TBO) maintains the same phase from northern summer in South Asia to southern summer in Australia, and how the reversed phase can last through three locally inactive seasons to the next monsoon, are studied by a simple tropical atmosphere-ocean-land model. The model has five boxes representing the South Asian and Australian monsoon regions and the equatorial Indian and western and eastern Pacific Oceans. The five regions interact with each other through the SSTmonsoon, evaporation-wind, monsoon-Walker circulation, and wind stress-ocean thermocline feedbacks.

A biennial oscillation emerges in a reasonable parameter regime, with model SST and wind variations resembling many aspects of the observed TBO. Warm SST anomalies (SSTA) in July in the equatorial Indian Ocean cause an increase of surface moisture convergence into South Asia, leading to a stronger monsoon. The monsoon heating on one hand induces a westerly wind anomaly in the Indian Ocean, and on the other hand intensifies a planetary-scale east-west circulation leading to anomalous easterlies over the western and central Pacific. The westerly anomaly over the Indian Ocean decreases the local SST, primarily by evaporation-wind feedback. The easterly anomaly in the central Pacific causes a deepening of the ocean thermocline in the western Pacific therefore increasing the subsurface and surface temperatures. In addition, a modest easterly anomaly in the western Pacific opposes the seasonal mean westerlies so evaporation is reduced. These effects overwhelm those of the cold zonal advection and anomalous upwelling. The net result is warm SSTA persisting in the western Pacific through northern fall, leading to a stronger Australian monsoon.

Meanwhile, the warming in the western Pacific also induces a stronger local Walker cell and thus a surface westerly anomaly over the Indian Ocean. This westerly anomaly helps the cold SSTA to persist through the succeeding seasons, leading to a weaker Asian monsoon in the following summer. During northern winter the westerly anomaly associated with the stronger Australian monsoon, through anomalous ocean downwelling and reduction of evaporation (when the seasonal mean wind is easterly), reinvigorates the warm SSTA in the western Pacific, which has been weakened by the slow cold advection from the eastern Pacific. This further intensifies the eastern Walker cell and helps to keep the eastern Pacific cold.

The authors' theory indicates that the TBO is an inherent result of the interactions between northern summer and winter monsoon and the tropical Indian and Pacific Oceans. Thus, it is an important component of the tropical ocean-atmosphere interaction system, separate from the El Niño-Southern Oscillation. While the eastern Pacific plays only a passive role in this mechanism, the western Pacific-Maritime Continent region is crucially important. It serves as a bridge in space and time, both in connecting the convection anomaly from the northern summer to the northern winter monsoon and in channeling the feedback of the northern winter monsoon to the Indian Ocean.
\end{abstract}

\section{Introduction}

The interannual variability of the Indian and Australian monsoon rainfall exhibits a remarkable biennial (or quasi-biennial) oscillation feature (Mooley and Parthasarathy 1984; Yasunari and Suppiah 1988; Yasunari 1990, 1991; Tian and Yasunari 1992; Shen and Lau 1995; Webster et al. 1998). This biennial oscillation, referred to as the tropospheric biennial oscillation (TBO) by Meehl $(1994,1997)$ in order to differentiate

Corresponding author address: Dr. C.-P. Chang, Department of Meteorology, Naval Postgraduate School, Monterey, CA 93493 5100 .

E-mail: cpchang@nps.navy.mil it from the stratospheric quasi-biennial oscillation (Reed et al. 1961), is associated with variations in the tropical atmospheric circulation and sea surface temperature (SST) over the tropical oceans (Rasmusson and Carpenter 1982; Meehl 1987; Kiladis and van Loon 1988; Ropelewski et al. 1992; Lau and Yang 1996). It appears that TBO as a prominent feature of the Asian-Australian monsoon may involve strong coupling and interactions between the atmosphere, ocean, and land surface.

One important feature of the atmospheric convection associated with the TBO over the Asian-Australian monsoon sector is that it exhibits a characteristic spatial structure and seasonality. Meehl $(1987,1993)$ stratified oceanic and atmospheric data according to whether the Asian monsoon is stronger or weaker relative to pre- 


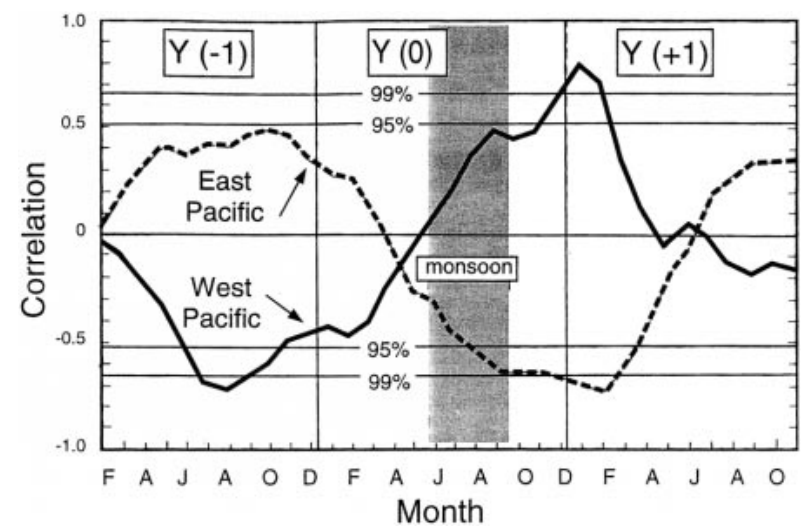

FIG. 1. Lagged correlations between the Indian monsoon rainfall anomaly and the SST anomaly in the western Pacific Ocean $\left(0^{\circ}-8^{\circ} \mathrm{N}\right.$, $130^{\circ}-150^{\circ} \mathrm{E}$, solid curve $)$ and the eastern Pacific Ocean $\left(0^{\circ}-8^{\circ} \mathrm{N}\right.$, $170^{\circ}-150^{\circ} \mathrm{W}$, dashed curve). Here $\mathrm{Y}(-1)$ and $\mathrm{Y}(+1)$ refer to the year before and after the reference year (Y0) (from Yasunari (1990).

vious and following seasons and noted a specific TBO pattern with a distinct seasonal sequence. Anomalies in convection (represented by outgoing longwave radiation) start over the Indian monsoon region during northern summer and propagate southeastward in the course of the seasonal march from northern summer to winter. That is, the condition of strong (or weak) convection over India and Southeast Asia during the summer monsoon persists over the Indonesian maritime continent and Australian monsoon region in the succeeding autumn and winter, following the seasonal migration of the convection center.

While the anomalies associated with the TBO move and develop continuously from northern summer to the following winter season, they become stationary and decay between northern winter and the following northern summer (Yasunari 1990; Tomita and Yasunari 1996). This temporal asymmetry of the TBO is clearly demonstrated from the lagged correlation between the Indian monsoon rainfall and SSTs in the western and eastern Pacific (Fig. 1, from Yasunari 1990). The lag correlation gradually increases after the summer monsoon season and reaches its maximum in the following winter. On the other hand, the correlation between the monsoon and SSTs in the previous winter is relatively low. A similar lag correlation relationship was also found for the East Asian summer monsoon rainfall (Shen and Lau 1995). These results suggest that the anomalous convective heating associated with the Asian summer monsoon may play an active role in forming or triggering the anomalous SST in the equatorial Pacific. Since during strong events the SST anomalies (SSTA) resemble the El Niño-La Niña conditions, this temporal asymmetry suggests that the impact of the Asian monsoon on the El Niño may be greater than the impact of the El Niño on the monsoon variations.

Ropelewski et al. (1992) documented from observational data the temporal and spatial structure of the
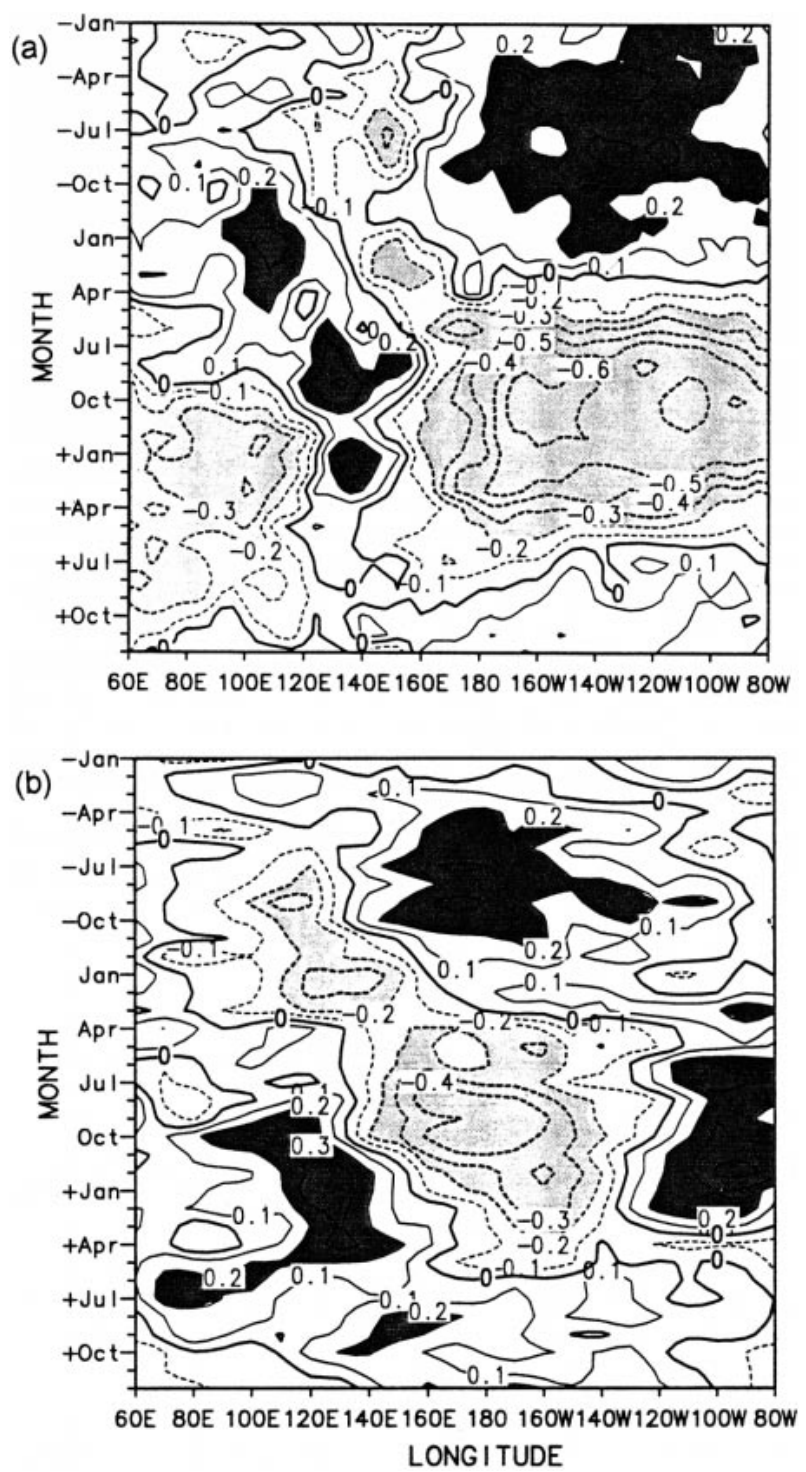

FIG. 2. Lagged correlations of Indian monsoon rainfall with (a) SST along $5^{\circ} \mathrm{N}-5^{\circ} \mathrm{S}$ and (b) surface winds along $6^{\circ} \mathrm{N}-6^{\circ} \mathrm{S}$. The correlations are computed over a 3-yr time domain from the Jan $1 \mathrm{yr}$ before to the Dec $1 \mathrm{yr}$ after the monsoon (from Lau and Yang 1996).

biennial and lower-frequency oscillations in both SST and surface wind fields over the equatorial Indian and Pacific Oceans. They suggested a possible linkage between the biennial variability and the monsoon circulation. The interrelationship between the Indian monsoon and SST and winds in the equatorial oceans are further studied by Lau and Yang (1996). Their lagged correlation map (Fig. 2) shows that prior to a strong Indian monsoon, SSTA tend to be positive in the equatorial Indian Ocean and the eastern and central equatorial Pacific, but they tend to be negative in the western equatorial Pacific north of Australia. Specifically, the equatorial eastern-central Pacific is occupied by warm anomalies for the entire preceding calendar year until 


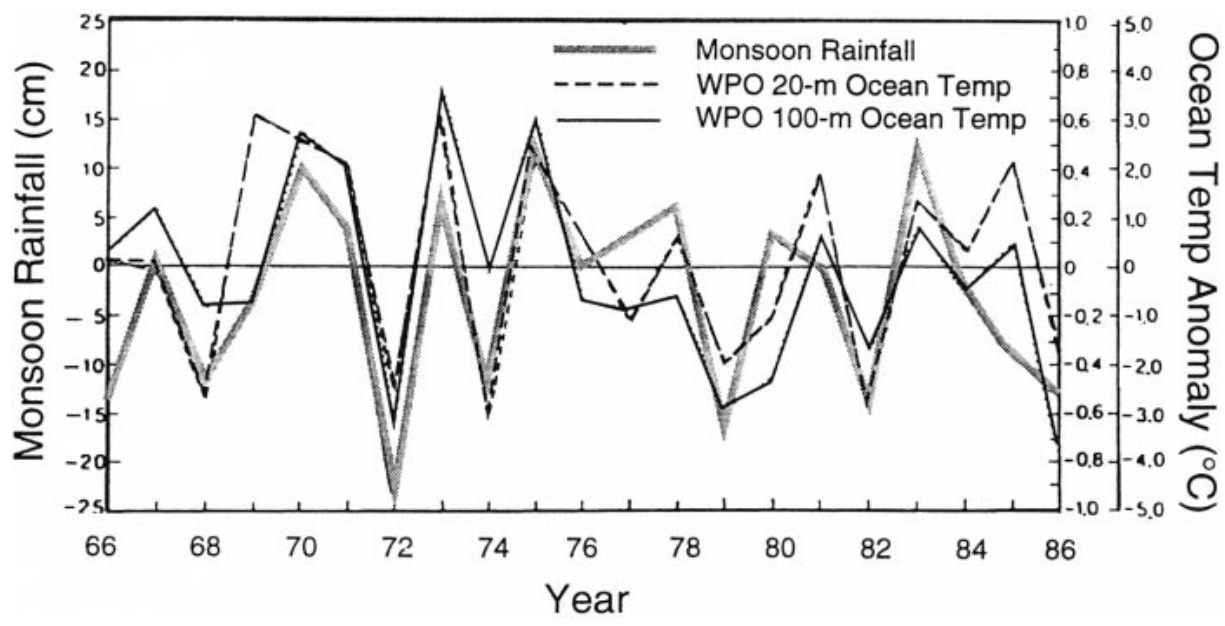

FIG. 3. Time series of the Indian monsoon rainfall (thick gray line) and the upper-ocean temperature at $20 \mathrm{~m}$ (dashed line) and $100 \mathrm{~m}$ (thin line) averaged along $137^{\circ} \mathrm{E}$ between $2^{\circ}$ and $10^{\circ} \mathrm{N}$ in the following Jan (from Yasunari 1990).

about March of the same year, and the equatorial Indian Ocean experiences warm anomalies from the preceding October through the boreal spring. By contrast, in the western equatorial Pacific cold anomalies prevail during most of the preceding 18 months.

Corresponding to these presummer SSTA, Fig. 2b shows that the wind anomaly is mostly westerly in the central Pacific and easterly in the Indian Ocean. Near the start of the strong Indian monsoon, easterly anomalies develop over the Pacific basin between approximately $130^{\circ} \mathrm{E}$ and $130^{\circ} \mathrm{W}$. This development occurs near simultaneously with the development of significant negative SSTA in the eastern-central Pacific and positive SSTA in the western Pacific. Over the Indian Ocean, westerly anomalies are established following the strong monsoon and are accompanied by the decrease of the local SST. Similar to the SST variations, a strong Indian monsoon is often followed by a deeper thermocline and warmer water in the western Pacific and a shallower thermocline and colder water in the eastern Pacific (Yasunari 1990; Matsumoto and Yamagata 1991; Meehl 1993). The high correlation between the Indian rainfall and the following January subsurface ocean temperatures in the western equatorial Pacific at the biennial scale can be seen in Fig. 3 (from Yasunari 1990).

Several theories have been proposed to understand the origin and nature of the TBO. Nicholls (1978) first hypothesized that the TBO results from the modulation/ amplification of the seasonal cycle due to opposite feedback's between the surface wind and pressure during a wet and dry season in the Indonesia-Northern Australia region. Meehl (1987, 1993) substantiated Nicholls' hypothesis and proposed a conceptual mechanism that includes a large-scale east-west circulation that links the strength of the monsoon with the equatorial eastern $\mathrm{Pa}$ cific SST and a memory effect of the tropical ocean west of the South Pacific convergence zone (SPCZ). In a "strong year" the Indian summer monsoon is strengthened by an anomalous large-scale east-west circulation associated with a colder eastern Pacific. This is followed by a southeastward progression of a stronger annualcycle convection over the warm SSTA west of the SPCZ, so that by northern winter the Australian monsoon is also strengthened. The stronger convection moves into the South Pacific High region in northern spring and induces anomalous westerlies in the equatorial Pacific, which contributes to a warming and reversal of the eastern Pacific SSTA and the start of the "weak" year. The process is augmented by a memory effect in which a strong monsoon cools local SSTs through various air-sea feedback processes (such as evaporation and ocean mixing). The large capacity of the ocean helps to maintain the cold SSTA, leading to a weak monsoon the next year.

To identify the processes that can help a reversal of the monsoon anomalies from one summer to the next, Meehl (1994, 1997) further considered the impact of land surface and midlatitude processes. The basic premise is that the pattern of tropical anomalous convective heating associated with anomalous SSTs during northern winter can remotely force a favorable long-wave anomaly in the northern midlatitude. This midlatitude circulation tends to maintain anomalous land surface temperatures over South Asia during northern winter and spring, in such a way that the land-sea temperature gradient will favor the reversal of the monsoon anomaly in the following summer. The midlatitude linkage was also considered by Tomita and Yasunari (1996), who proposed that the anomalous SST in the South China Sea served as the agent to connect the Asian summer monsoon and midlatitude winter circulation pattern. More recently, Clarke et al. (1998) expanded on Nicholls' $(1978,1979,1984)$ theory and developed a model in which the interaction between the mean seasonal wind 
cycle and evaporation excites a biennial mode in the western equatorial Pacific, which may then drive a biennial oscillation in the Indian Ocean.

While the above theoretical studies have advanced our understanding of the observed TBO, none are satisfactory in explaining the oscillation completely on a physical basis. The local feedback mechanism in Nicholls' and Meehl's pioneering work provides a basis to explain the reversal of the local SSTA following an anomalous monsoon season in India in northern summer or in the maritime continent/northern Australia in northern winter. However, the transition mechanism of the tropical large-scale east-west circulation in Meehl's (1987) earlier conceptual model is questionable. In particular, he assumed that the Indian monsoon is affected by the equatorial eastern Pacific SSTA through the eastwest circulation. On the other hand, Krishnamurti (1971) and Krishnamurti et al. (1973) showed convincing evidence that this circulation is driven by the deep convection of the Asian monsoon, so the anomalous strength of the east-west circulation is a result of the strength of the Asian monsoon rather than the other way around. Furthermore, Yasunari's (1990) asymmetric lag correlation (Fig. 1) shows that only the postsummer equatorial eastern Pacific SST has a significant correlation with the Indian summer monsoon. Thus, it is more likely that the monsoon directly influences the eastern Pacific SST on the TBO scale. This may be expected since a variation of the monsoon strength immediately affects the east-west circulation through latent heat release in the middle-upper troposphere. On the other hand, a small cold anomaly (order of $-1 \mathrm{~K}$, Ropelewski et al. 1992) in the eastern Pacific cold tongue is much less likely to play an active role to pull air mass out of the Asian monsoon through the east-west circulation.

If the eastern Pacific SSTA do not play an active role in TBO, a mechanism will also be required to explain the SSTA in the western Pacific, as one can no longer preassume the western Pacific SSTA should be warm during a "strong" year. Related to this assumption is another important part of Meehl's (1987) hypothesis that the southeastward progression of the anomalous annual cycle convection links the TBO phase of the Australian monsoon to that of the preceding Indian monsoon. This progression hypothesis was also questioned by Clarke et al. (1998), who pointed out that it implies the phase of the TBO should depend strongly on the timing of the seasonal cycle. But Clarke et al.'s observational analysis indicates that this is not always true. A biennial oscillation occurs in a region where there is no clear seasonal maximum.

The midlatitude connection proposed by Meehl (1997) allows a TBO phase transition in northern summer without the eastern Pacific transition mechanism proposed by Meehl's (1987) earlier model. However, the process acts only during the transition from northern winter to northern summer.

The Nicholls-Clarke et al. hypothesis emphasizes the wind-evaporation feedback in the tropical air-sea interaction. In order to produce an oscillation, Clarke et al. (1998) introduced an empirical equation with a time lag for the equatorial zonal wind anomaly to correlate with the SSTA in the western equatorial Pacific. Their work highlights the crucial importance of this time lag in determining the oscillation in their model. However, the physical argument of this correlation that the wind anomaly responds to deep convection heating is inconsistent with the 1-3-month time lag, since the adjustment time in the atmosphere is much faster. This mechanism also does not explain the substantial TBO signal in the Indian Ocean region.

In addition, all theories depending on midlatitude processes involve complex interactions both within the Tropics and between the tropics and the midlatitude. These processes are difficult to track analytically and need to be studied by GCM experiments. The experiments depend crucially on the GCM's ability to accurately simulate the evolution of the interannual anomalous patterns, which is still a substantial challenge in the Asian monsoon region.

Thus, many important questions remain. The most notable ones are: What determines the coherent temporal and spatial evolution of the TBO, and what types of air-sea-land feedback processes are relevant and responsible for the development and phase transition of the TBO? Why is a strong Asian monsoon followed by a strong Australian monsoon? What factors determine the asymmetric evolution of the TBO from northern summer to northern winter, and from northern winter to the following summer?

This work is an attempt to explain the TBO within a simple theoretical framework. In the present paper we will consider tropical processes only, so that the results are analytical and traceable directly to basic physical mechanisms. We will assume that the strong mass outflow over the Asian-Australian monsoon region at upper levels drives the planetary-scale east-west circulation in the Tropics (Krishnamurti 1971; Krishnamurti et al. 1973). Changes in both the intensity and the position of this east-west circulation, particularly its equatorial portion that coincides with the Walker circulation (Bjerknes 1969), may affect the SST variations (Philander 1990). On the other hand, any direct effect of eastern Pacific SST on the east-west circulation will be excluded. In addition, we will include the effects of the Walker circulation between the western Pacific and the Indian Ocean. These effects turn out to play crucial roles in answering the key questions related to the spatial structures and the temporal transitions of the TBO.

Section 2 describes the construction of a simple model that includes specific air-sea-land interaction processes that connect the Asian and Australian monsoons to the Indian and Pacific Ocean SST and wind changes. Section 3 presents the model result, which is used to determine the temporal and spatial structures of the TBO. These structures are discussed in section 4 where the 


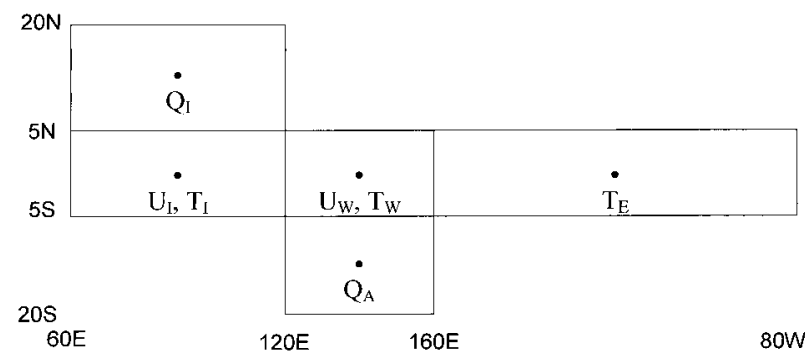

FIG. 4. The model with five boxes: South Asia and Australia monsoon regions, and Indian Ocean, and western and eastern equatorial Pacific. See text for details.

main physical processes involved in the complex interactions are elucidated. Section 5 gives some concluding remarks.

\section{Model}

\section{a. Governing equations}

A simple five-box (as shown in Fig. 4) model is constructed to study tropical ocean-atmosphere-land interactions. Along the equator the ocean is divided into three unequal-volume regions, with $T_{I}, T_{W}$, and $T_{E}$ representing, respectively, the SSTA in the Indian Ocean $\left(60^{\circ}-120^{\circ} \mathrm{E}\right)$, western Pacific-Maritime Continent $\left(120^{\circ}-160^{\circ} \mathrm{E}\right)$, and eastern Pacific $\left(160^{\circ} \mathrm{E}-80^{\circ} \mathrm{W}\right)$. The appendix gives the detailed derivation of the SST equations. The time rate of change of the SSTA in the Indian Ocean may be written as

$$
\begin{aligned}
\frac{d T_{I}}{d t}= & -\lambda \Delta \bar{q}_{I} \frac{\bar{U}_{I} U_{I}}{V_{0}}-\lambda V_{0} \kappa T_{I}-u_{I} \bar{T}_{I}^{(x)}-w_{I} \bar{T}_{I}^{(z)} \\
& -\frac{\bar{w}_{I}}{h} T_{I},
\end{aligned}
$$

where the first two terms in the right side of (1) represent a linear form of surface wind-evaporation feedback, the third term the zonal temperature advection, and the last two terms the vertical temperature advection. In (1), $U$, $u$, and $w$ denote, respectively, the surface zonal wind, ocean zonal current and vertical velocity at the base of the mixed layer; $\Delta q$ is air-sea specific humidity difference; $T^{(x)}$ and $T^{(z)}$ are zonal and vertical ocean temperature gradients, respectively, where subscript $I$ stands for Indian Ocean and an overbar represents the timemean basic-state field; $V_{0}$ denotes a constant mean surface wind speed; and $\lambda=\rho_{a} c_{D} L / \rho c_{w} h$, where $\rho$ and $\rho_{a}$ are the density of water and surface air; $\kappa$ is an empirical constant relating SST and specific humidity, $c_{w}$ is the specific heat of water, $c_{D}$ is the drag coefficient, $L$ is the latent heat, and $h$ is the mean depth of the ocean mixed layer.

The change of SSTA in the western Pacific is given by

$$
\begin{aligned}
\frac{d T_{W}}{d t}= & -\lambda \Delta \bar{q}_{W} \frac{\bar{U}_{W} U_{W}}{V_{0}}-\lambda V_{0} \kappa T_{W}-u_{C} \bar{T}_{C}^{(x)}-\bar{u}_{C} T_{C}^{(x)} \\
& -w_{W} \bar{T}_{W}^{(z)}-\frac{\bar{w}_{W}}{h}\left(T_{W}-\gamma \eta_{W}\right),
\end{aligned}
$$

where $\eta$ denotes the thermocline depth anomaly and $\gamma$ represents the strength of subsurface ocean temperature variations associated with the thermocline movement, and subscripts $W$ and $C$ denote the western and central equatorial Pacific, respectively. The annual mean zonal wind in the equatorial western Pacific is very small, but the first term may be important if seasonal-mean wind (westerly during northern summer and easterly during northern winter) is considered. Thermocline variation is included because it is very important in the Pacific on the interannual timescale (Philander 1990; Meehl 1993). Even though in the equatorial western Pacific vertical motion associated with the mean ocean circulation is downward, the effect of wind-induced vertical mixing, which is proportional to the third power of surface wind speed (Kraus and Turner 1967), makes the mean vertical velocity weakly positive. Thus, the thermocline variations can affect western Pacific SSTs through subsurface ocean temperature changes.

Similarly, the SST equation in the eastern Pacific reads

$$
\frac{d T_{E}}{d t}=-\lambda V_{0} \kappa T_{E}-w_{E} \bar{T}_{E}^{(z)}-\frac{\bar{w}_{E}}{h}\left(T_{E}-\gamma \eta_{E}\right) .
$$

The change of the thermocline depth in the Pacific is determined by the change in the zonal wind stress in the central Pacific, based on a Sverdrup balance (Neelin 1991; Li 1997); that is,

$$
\begin{aligned}
g^{\prime} \frac{\partial \eta}{\partial x} & =\frac{\tau^{x}}{\rho H}=\frac{\alpha U_{C}}{\rho H} \text { or } \\
\eta_{W} & =-\eta_{E}=-\frac{L_{E W} \alpha U_{C}}{2 \rho g^{\prime} H},
\end{aligned}
$$

where $g^{\prime}$ is reduced gravity, $H$ the mean depth of the ocean thermocline, $L_{E W}$ the distance between the western and eastern equatorial Pacific, and $\alpha=\rho_{a} c_{D} V_{0}$.

Observations indicate that positive SSTAs often occur over the equatorial Indian Ocean prior to a strong Indian monsoon (Ropelewski et al. 1992; Lau and Yang 1996). Similarly, neighboring positive SSTAs exist before a strong Australian monsoon. As a result, moisture convergence into the monsoon region increases (Meehl 1994, 1997). The anomalously warm ocean also has a negative impact on the monsoon heating, as it reduces the land-sea thermal contrast and induces anomalous divergence out of South Asia. However, as will be shown in the scale analysis in section $2 b$, this effect is relatively small. The net effect of the positive SSTA is the intensification of convective heating in the monsoon region. By assuming the monsoon heating is proportional to the anomalous moisture convergence in the 


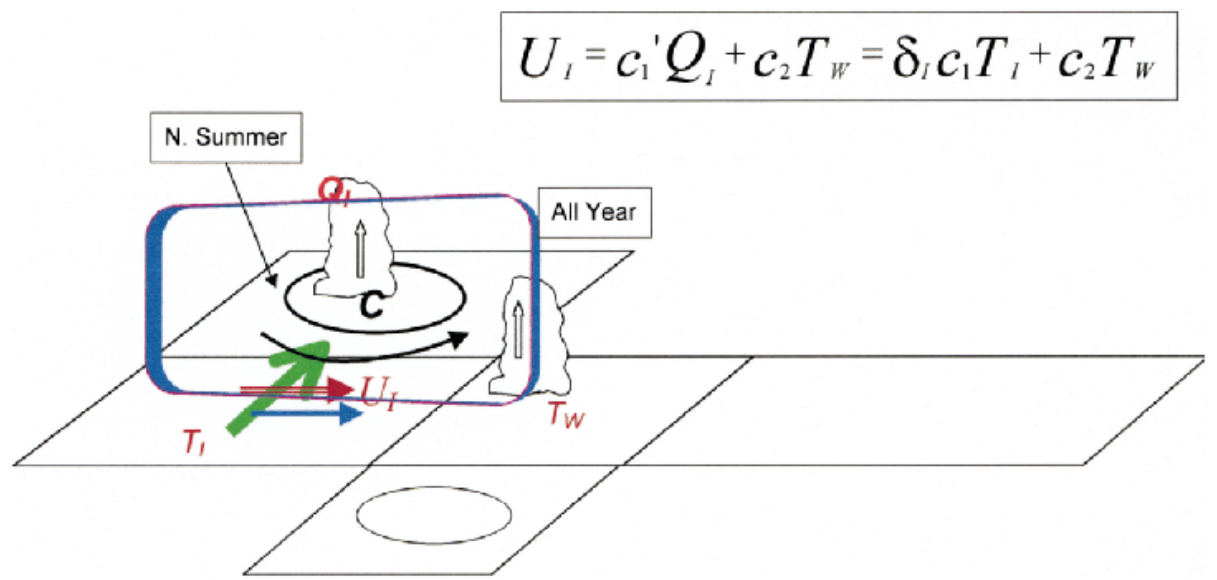

FIG. 5a. Schematic diagram showing the relationship between $U_{I}$ and $T_{I}$ and $T_{W}$. The Indian Ocean SST determines the anomalous moisture convergence (green thick arrow) into South Asia, which in turn determines the convective heating $\left(Q_{I}\right)$ and cyclonic vorticity $(\mathbf{C})$ of the northern summer monsoon, therefore relating $T_{I}$ and $U_{I}$ during northern summer only. The western equatorial Pacific SST determines the strength of the western Walker cell. This cell operates in all four seasons and causes $T_{I}$ to influence $U_{I}$ continuously throughout the year.

$$
U_{W}=c_{3}^{\prime} Q_{A}-c_{4}^{\prime} Q_{I}=\delta_{A} c_{3} T_{W}-\delta_{i} c_{4} T_{t}
$$

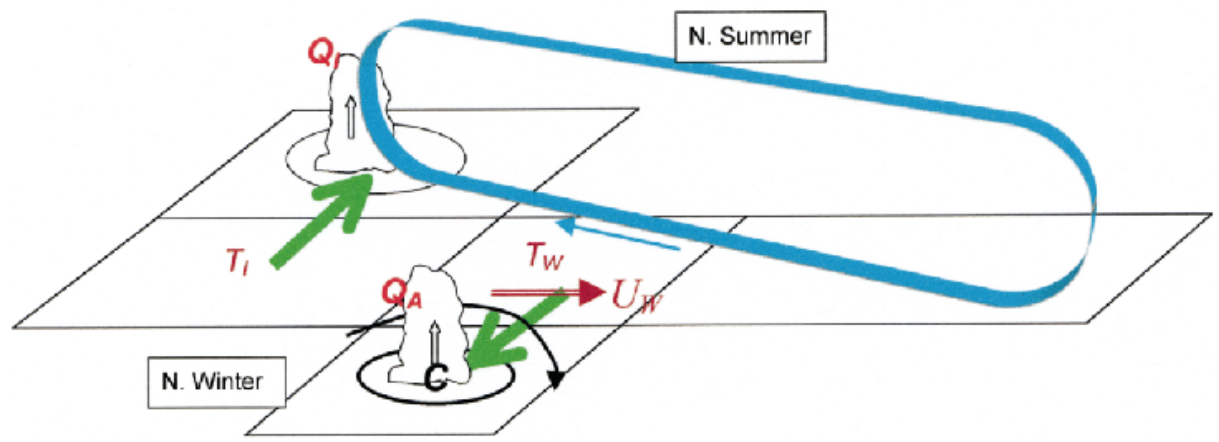

FIG. 5b. Schematic diagram showing the relationship between $U_{W}$ and $T_{I}$ and $T_{W}$. The western equatorial Pacific SST determines anomalous moisture convergence (green thick arrow) into Australia, which in turn determines the convective heating $\left(Q_{A}\right)$ and cyclonic vorticity $(\mathbf{C})$ of the southern summer monsoon, therefore relating $T_{W}$ and $U_{W}$ during northern winter only. The strength of the east-west circulation indicated in the diagram depends on the convective heating of the South Asian monsoon, thus it links the Indian Ocean SST with $U_{W}$ during northern summer.

atmospheric boundary layer, the SST-monsoon feedback process may be parameterized as

$$
Q_{j}=-\delta_{j} b \rho_{a} \Delta z L(\nabla \cdot \overline{\mathbf{V}} q)_{j},
$$

where subscript $j=I$ or $A$, denoting the Indian or Australian monsoon; $\delta$ represents the seasonality of the monsoon heating with $\delta_{I}=1$ for June-August and $=$ 0 otherwise, and $\delta_{A}=1$ for December-February and $=0$ otherwise; $b$ is a fraction of the moisture convergence that condenses out and releases the latent heat following Kuo (1974), $\Delta z$ is the depth of the atmospheric boundary layer, and $q_{j}=(0.972 T-8.92) \times$ $10^{-3}$ is the initial surface air specific humidity imme- diately before the onset of the monsoon, which is a function of SST (T) according to an empirical analysis (Li and Wang 1994).

On the interannual timescale, surface zonal winds over the Indian Ocean consist of two major parts, as illustrated in the following equation:

$$
U_{I}=c_{1}^{\prime} Q_{I}+c_{2} T_{W}=\delta_{I} c_{1} T_{I}+c_{2} T_{W} .
$$

Here the first term on the right-hand side gives the direct response to anomalous monsoon heating and the second part reflects the change of intensity of a Walker cell over the Indian Ocean due to the SST change in the maritime continent. Equation (6) is schematically illustrated in Fig. 


$$
\begin{aligned}
U_{C} & =-c_{5}{ }^{\prime} Q_{A}-c_{6}{ }^{\prime} Q_{1}+\frac{A}{\varepsilon L_{E W}}\left(T_{E}-T_{W}\right) \\
& =-\delta_{A} c_{3} T_{W}-\delta_{l} c_{6} T_{1}+\frac{A}{\varepsilon L_{E W}}\left(T_{E}-T_{W}\right)
\end{aligned}
$$

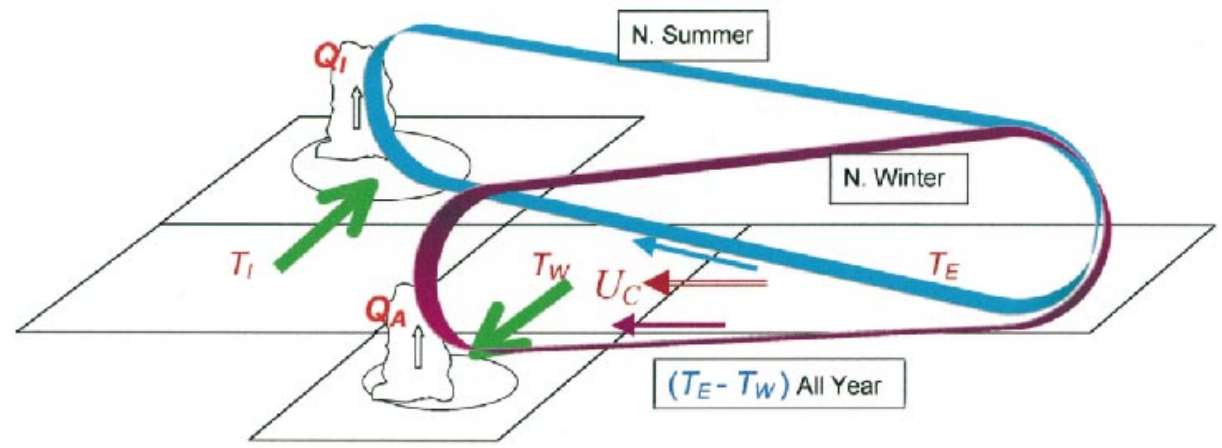

FIG. 5c. Schematic diagram showing the relationship between $U_{C}$ and $T_{I}, T_{W}$, and $T_{E}$. Through the strength of the east-west circulations, $U_{C}$ is affected by the Indian Ocean SST during northern summer and the western equatorial Pacific SST during northern winter. In addition, the SST gradient between the eastern and western equatorial Pacific influences $U_{C}$ throughout the year.

5a. The surface wind in the western Pacific, on the other hand, is determined by the anomalous heating over Australia and by the Indian monsoon, which, by altering the planetary-scale east-west circulation, changes the surface wind in both the western and central equatorial Pacific (Barnett et al. 1989; Meehl 1997):

$$
U_{W}=c_{3}^{\prime} Q_{A}-c_{4}^{\prime} Q_{I}=\delta_{A} c_{3} T_{W}-\delta_{I} c_{4} T_{I} .
$$

This equation is schematically represented in Fig. 5 b.

In addition to the influence by anomalous South Asian and Australian monsoon heating, the wind in the central equatorial Pacific is also affected by zonal SST gradients along the equator (Lindzen and Nigam 1987) so that the total anomalous zonal wind in the central Pacific is written as

$$
\begin{aligned}
U_{C} & =-c_{5}^{\prime} Q_{A}-c_{6}^{\prime} Q_{I}+\frac{A}{\varepsilon L_{E W}}\left(T_{E}-T_{W}\right) \\
& =-\delta_{A} c_{5} T_{W}-\delta_{I} c_{6} T_{I}+\frac{A}{\varepsilon L_{E W}}\left(T_{E}-T_{W}\right),
\end{aligned}
$$

where $A$ is an SST-gradient momentum forcing coefficient (Wang and $\mathrm{Li} \mathrm{1993),} \mathrm{and} \varepsilon$ is an atmospheric Rayleigh friction coefficient. Equation (8) is represented schematically in Fig. 5c.

The surface wind in turn drives the ocean surface current and induces ocean vertical overturning. A simplified Cane-Zebiak (Cane 1979; Zebiak and Cane 1987; Li 1997) model is used to calculate the ocean surface currents and Ekman pumping velocity along the equatorial Indian and Pacific Oceans. They are

$$
\begin{aligned}
u_{I} & =\frac{\alpha U_{I}}{\rho h r}, \\
w_{I} & =-\frac{(H-h) \beta \alpha U_{I}}{\rho H r^{2}}, \\
u_{C} & =\frac{\alpha U_{C}}{\rho h r}, \\
w_{W} & =-\frac{(H-h) \beta \alpha U_{W}}{\rho H r^{2}}+\frac{2 h(H-h) u_{C}}{L_{E W}}, \\
w_{E} & =-\frac{(H-h) \beta \alpha U_{C} \sigma}{\rho H r^{2}}-\frac{2 h(H-h) u_{C}}{L_{E W}} .
\end{aligned}
$$

Here $\beta$ denotes the planetary vorticity gradient, $H$ is the mean depth of the ocean thermocline, and $r$ is a friction coefficient in the oceanic Ekman layer. The vertical velocities in (12) and (13) consist of both meridional and zonal convergence components. The meridional component of the Ekman convergence in the eastern Pacific is estimated with a ratio of $\sigma$ from its counterpart in the central Pacific. Table 1 lists the standard values of the model parameters, where the interactive coefficients $c_{1}, c_{2}, \ldots, c_{6}$ are determined by a scale analysis given in the next subsection.

\section{b. Scale analysis for interactive coefficients}

The characteristic scale for the vertical motion over the monsoon region can be deduced from a primary balance between the adiabatic process and diabatic heating. Following Wang and Li's (1993) 2.5-layer model, we have 
TABLE 1. List of values of model parameters.

\begin{tabular}{|c|c|c|c|}
\hline$\rho_{a}$ & $1.2 \mathrm{~kg} \mathrm{~m}^{-3}$ & $\bar{T}_{I}^{(x)}$ & $2 \times 10^{-7} \mathrm{~K} \mathrm{~m}^{-1}$ \\
\hline$c_{D}$ & $1.5 \times 10^{-3}$ & $\bar{T}_{C}^{(x)}$ & $-5 \times 10^{-7} \mathrm{~K} \mathrm{~m}^{-1}$ \\
\hline$V_{o}$ & $5 \mathrm{~m} \mathrm{~s}^{-1}$ & $\overline{U_{I}}$ & $3 \mathrm{~m} \mathrm{~s}^{-1}$ \\
\hline$h$ & $50 \mathrm{~m}$ & $\overline{U_{W}}$ n. summer & $2 \mathrm{~m} \mathrm{~s}^{-1}$ \\
\hline$H$ & $150 \mathrm{~m}$ & $\overline{U_{W}}$ n. winter & $-2 \mathrm{~m} \mathrm{~s}^{-1}$ \\
\hline$g^{\prime}=\frac{c_{o}^{2}}{H}$ & $\frac{1.5^{2}}{150} \mathrm{~m} \mathrm{~s}^{-2}$ & $\bar{T}_{I}^{(z)}$ & $0.01 \mathrm{~K} \mathrm{~m}^{-1}$ \\
\hline$r$ & $10^{-5} \mathrm{~s}^{-1}$ & $\bar{T}_{W}^{(z)}$ & $0.01 \mathrm{~K} \mathrm{~m}^{-1}$ \\
\hline$\varepsilon$ & $10^{-5} \mathrm{~s}^{-1}$ & $\bar{T}_{E}^{(z)}$ & $0.1 \mathrm{~K} \mathrm{~m}^{-1}$ \\
\hline$\varepsilon_{y}$ & $3 \times 10^{-5} \mathrm{~s}^{-1}$ & $\bar{u}_{C}$ & $-0.3 \mathrm{~m} \mathrm{~s}^{-1}$ \\
\hline$\sigma$ & 0.9 & $\bar{w}_{I}$ & $2 \times 10^{-6} \mathrm{~m} \mathrm{~s}^{-1}$ \\
\hline$\gamma$ & $0.1 \mathrm{~K} \mathrm{~m}^{-1}$ & $\bar{w}_{W}$ & $2 \times 10^{-6} \mathrm{~m} \mathrm{~s}^{-1}$ \\
\hline$\kappa$ & $7 \times 10^{-4} \mathrm{~K}^{-1}$ & $\bar{w}_{E}$ & $10^{-5} \mathrm{~m} \mathrm{~s}^{-1}$ \\
\hline$b$ & 0.9 & $\Delta \overline{q_{I}}=\Delta \overline{q_{W}}$ & $5.6 \times 10^{-3}$ \\
\hline$\Delta z$ & $1500 \mathrm{~m}$ & $L_{E W}$ & $8 \times 10^{6} \mathrm{~m}$ \\
\hline$L_{y}$ & $1.5 \times 10^{6} \mathrm{~m}$ & $L_{I E}$ & $2 \times 10^{7} \mathrm{~m}$ \\
\hline
\end{tabular}

$$
S_{2} \omega_{2}=-\frac{R}{c_{p} p_{2}} Q_{2},
$$

where $S_{2}=2 c_{a}^{2} / \Delta p^{2}$ is the midtropospheric static stability parameter, $c_{a}=50 \mathrm{~m} \mathrm{~s}^{-1}$ is the first baroclinic mode gravity wave speed, $\Delta p=375 \mathrm{hPa}$ is the halfdepth of the free atmosphere; $\omega_{2}$ denotes the $p$-coordinate vertical velocity at $p_{2}=475 \mathrm{hPa}$ (the midtroposphere), $R$ the gas constant of dry air, and $Q_{2}$ represents the atmospheric heating that is proportional to the anomalous precipitation rate.

We assume that precipitation over the monsoon region is primarily determined by boundary-layer moisture convergence. The change of SST in the equatorial oceans may have both positive and negative effects on monsoon rainfall. A positive SST anomaly in the Indian Ocean, on the one hand, causes an increase of the local specific humidity, $q^{\prime}$, and thus an increase of the surface moisture convergence. On the other hand, it reduces the land-sea temperature gradient and induces an anomalous surface divergence, $\boldsymbol{\nabla} \cdot \mathbf{V}^{\prime}$, and thus a decrease of the rainfall. The two processes can be written as

$$
P_{r}^{(S A)}=b \rho_{a} \Delta z\left[(-\boldsymbol{\nabla} \cdot \overline{\mathbf{V}}) q^{\prime}+\left(-\boldsymbol{\nabla} \cdot \mathbf{V}^{\prime}\right) \bar{q}\right]^{(S A)} .
$$

Here $P_{r}$ is anomalous precipitation, superscript $(S A)$ indicates South Asia, $q^{\prime}=0.972 \times 10^{-3} T_{I}=c_{q} T_{I}$ and $\boldsymbol{\nabla} \cdot \mathbf{V}^{\prime}=\left(A / \varepsilon_{y} L_{y}^{2}\right) T_{I}$. Given $A=25, \varepsilon_{y}=3 \times 10^{-5}$ $\mathrm{s}^{-1}$, which is adapted from Li and Wang's (1994) calculation of direction- and latitude- dependent Rayleigh coefficients, $\boldsymbol{\nabla} \cdot \overline{\mathbf{V}}^{(S A)}=-2 \times 10^{-5} \mathrm{~s}^{-1}, \bar{q}=18 \times$ $10^{-3}$, and the parameter values in Table 1, (14)-(15) give

$$
\left|\frac{\omega_{2}^{(S A)}}{2 \Delta p}\right|=\frac{R L g}{4 c_{p} p_{2} c_{a}^{2}} P_{r}^{(S A)}=4 \times 10^{-7} \mathrm{~s}^{-1} \mathrm{~K}^{-1} T_{I} .
$$

The ascending of air mass over the South Asian mon- soon region is balanced by planetary-scale east-west circulations and a local Hadley cell with sinking motion in the Southern Hemisphere. Krishnamurti (1971) showed that the east-west cell over the Pacific is the major branch. Assuming that this cell involves 50\% of the total air mass in the circulations, and denoting $U_{C}^{(1)}$ and $L_{I E}$ as the low-level return flow strength and the zonal extent of the east-west cell, we have

$$
\left|\frac{U_{C}^{(1)}}{L_{I E}}\right|=50 \%\left|\frac{\omega_{2}^{(S A)}}{2 \Delta p}\right| .
$$

For the parameter values given in Table 1, the strength of the central Pacific zonal wind associated with the anomalous Indian monsoon heating based on (16)-(17) may be written

$$
U_{C}^{(1)}=-4 \mathrm{~m} \mathrm{~s}^{-1} \mathrm{~K}^{-1} T_{I} .
$$

Applying the same principal to the Australian monsoon region where horizontal length scale for the Pacific basin is about $70 \%$ of $L_{I E}$, we obtain another contribution to the central Pacific zonal wind:

$$
U_{C}^{(2)}=-2.8 \mathrm{~m} \mathrm{~s}^{-1} \mathrm{~K}^{-1} T_{W} .
$$

These two relationships give the values of $c_{5}=2.8 \mathrm{~m}$ $\mathrm{s}^{-1} \mathrm{~K}^{-1}$ and $c_{6}=4 \mathrm{~m} \mathrm{~s}^{-1} \mathrm{~K}^{-1}$ in (8). The relationship that links $U_{C}$ with $T_{I}$ also applies to $U_{W}$, as both will be affected by the anomalous planetary-scale east-west circulation produced by the anomalous South Asian monsoon. So the same consideration gives $c_{4}=4 \mathrm{~m}$ $\mathrm{s}^{-1} \mathrm{~K}^{-1}$ in (7).

The SSTA in the western equatorial Pacific-Maritime Continent excite anomalous local Hadley and Walker circulations. Krishnamurti et al. (1973), in a study of the northern winter monsoon, showed that the local Hadley and Walker circulations driven by the mean monsoon heating are nearly comparable in magnitude. Therefore we will assume the mass involved in the anomalous circulations are also equally distributed between the two. The Walker circulation has western and eastern branches, the former is a cell over the equatorial Indian Ocean. Based on the scaling argument used in (15)(17), the characteristic scale of the surface zonal wind over the Indian Ocean, $U_{I}^{(1)}$ (associated with the western Pacific SSTA), is given by

$$
\left|\frac{U_{I}^{(1)}}{L_{I W}}\right| \propto\left|\frac{\omega_{2}^{(W P)}}{2 \Delta p}\right|=\frac{R L g}{4 c_{p} p_{2} c_{a}^{2}} P_{r}^{(W P)} .
$$

Here the superscript (WP) denotes western Pacific. Different from the case in the monsoon region, the two moisture convergence terms over the western Pacific have the same sign as the SSTA. The precipitation rate in the western Pacific may be written:

$$
P_{r}^{(W P)}=b \rho_{a} \Delta z\left[\left(-\nabla \cdot \overline{\mathbf{V}}^{(W P)}\right) c_{q}+\bar{q}^{(W P)} \frac{A}{\varepsilon_{y} L_{y}^{2}}\right] T_{W} .
$$

Given $\boldsymbol{\nabla} \cdot \overline{\mathbf{V}}^{(W P)}=-2 \times 10^{-5} \mathrm{~s}^{-1}$ and $\bar{q}^{(W P)}=18 \times$ 
$10^{-3}$, same values as the Indian Ocean, and assuming the western branch represents one-half of the anomalous Walker circulation and therefore one-quarter of the total anomalous circulation, we have

$$
U_{I}^{(1)}=25 \%\left|\frac{\omega_{2}^{(W P)}}{2 \Delta p}\right| L_{I W}=1.6 \mathrm{~m} \mathrm{~s}^{-1} \mathrm{~K}^{-1} T_{W} .
$$

Therefore $c_{2}=1.6 \mathrm{~m} \mathrm{~s}^{-1} \mathrm{~K}^{-1}$ in (6).

The surface convergence associated with the anomalous heating over the monsoon region generates a positive anomalous vorticity. The steady solution for the anomalous vorticity may be written as

$$
\varepsilon \zeta=-f_{0} \boldsymbol{\nabla} \cdot \mathbf{V}=f_{0}\left|\frac{\omega_{2}}{\Delta p}\right|,
$$

where $\zeta$ is the relative vorticity and $f_{0}=3.3 \times 10^{-5}$ $\mathrm{s}^{-1}$ is the Coriolis parameter. Corresponding to the generation of the anomalous vorticity, surface zonal wind anomalies are excited to the south of the South Asian monsoon region and north of the Australian monsoon region. These zonal wind anomalies may be estimated by applying (20) to both regions:

$$
\begin{aligned}
& U_{I}^{(2)}=\frac{L_{y}}{\varepsilon} f_{0}\left|\frac{\omega_{2}}{\Delta p}\right|=4 \mathrm{~m} \mathrm{~s}^{-1} \mathrm{~K}^{-1} T_{I}, \\
& U_{W}^{(2)}=\frac{L_{y}}{\varepsilon} f_{0}\left|\frac{\omega_{2}}{\Delta p}\right|=4 \mathrm{~m} \mathrm{~s}^{-1} \mathrm{~K}^{-1} T_{W} .
\end{aligned}
$$

Thus, in (6) $c_{1}=4 \mathrm{~m} \mathrm{~s}^{-1} \mathrm{~K}^{-1}$ and in (7) $c_{3}=4 \mathrm{~m} \mathrm{~s}^{-1}$ $\mathrm{K}^{-1}$.

The above scale analysis provides estimates of the interactive coefficients used in (6)-(8). These values may also be compared with the biennially filtered surface wind and SSTA over the equatorial Indian and Pacific Oceans observed by Ropelewski et al. (1992). Their SST structure (their Fig. 9) indicates SSTA of $0.4^{\circ}-0.5^{\circ} \mathrm{C}$ in the Indian Ocean and their surface wind structure (their Fig. 14) indicates a zonal wind anomaly of 1.4-1.6 $\mathrm{m} \mathrm{s}^{-1}$. These values indicate the range of $c_{1}$, $c_{4}$, and $c_{6}$ to be 3-4 $\mathrm{m} \mathrm{s}^{-1} \mathrm{~K}^{-1}$, which are comparable to the results of our scale analysis.

\section{Results}

With the parametric values given in Table 1, Fig. 6 shows the time evolution of the model-simulated anomalous rainfall rates over the South Asian and Australian monsoon regions. The amplitude of the anomalous precipitation rate is $1.9 \mathrm{~mm} \mathrm{day}^{-1}$ in the former and 1.3 $\mathrm{mm}$ day $^{-1}$ in the latter. The solution is a pure biennial mode, with a stronger (weaker) Australian monsoon always following an intensified (weakened) South Asian rain season.

The time evolution of the model SST and zonal wind fields (Fig. 7) resembles most of the gross structure of
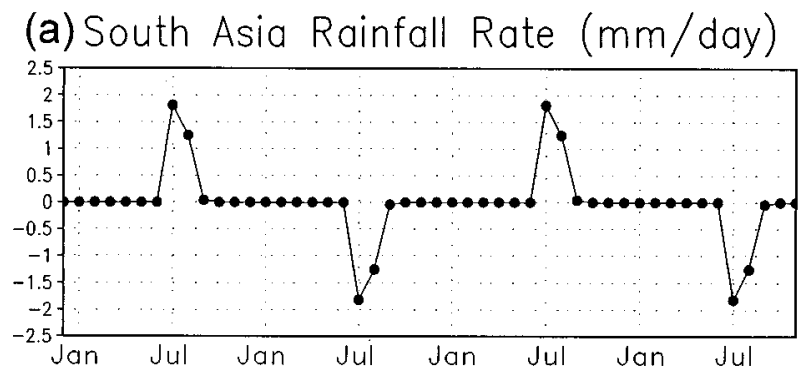

(b) Australia Rainfall Rate (mm/day)

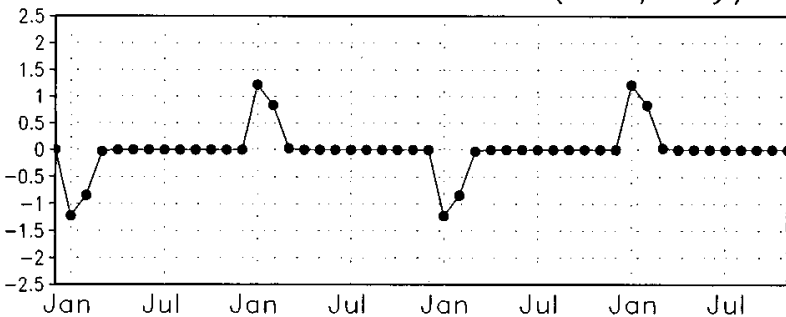

FIG. 6. Model anomalous rainfall rate $\left(\mathrm{mm} \mathrm{day}^{-1}\right)$ in (a) the South Asian monsoon region and (b) the Australian monsoon region.

the TBO observed by Lau and Yang (1996) along the equator as described in Fig. 2. The SSTA in the Indian Ocean and in the eastern Pacific are approximately in phase in time, and they are out of phase with that in the western equatorial Pacific. The amplitude of the SST oscillations is around $0.5 \mathrm{~K}$ in the Indian Ocean and the western Pacific, and is around $1.0 \mathrm{~K}$ in the eastern $\mathrm{Pa}-$ cific. Over the Indian Ocean, maximum westerly winds with amplitude about $2 \mathrm{~m} \mathrm{~s}^{-1}$ appear in July-September and are accompanied by an intensified Indian monsoon. Over the western Pacific-Maritime Continent, they occur in December-February with an amplitude of near $1.5 \mathrm{~m} \mathrm{~s}^{-1}$ and are associated with an intensified Australian monsoon. Thus, the model is capable of simulating the essential characteristics of the biennial oscillation. The main difference between Fig. 7 and observations is that the SSTA in the eastern Pacific start earlier (Lau and Yang 1996) in northern spring rather than July. This spring transition feature is most likely related to the phase transition of El Niño-Southern Oscillation (ENSO) (Webster and Yang 1992) that is excluded from the present model.

In addition to basic agreement with the observed TBO, signals of some of the observed detail features are also reflected in the simulated results. These include the delay of the maximum Indian Ocean SSTA relative to that of the eastern-central Pacific, the occurrence of two SSTA maxima in the western Pacific between northern fall and northern winter, and the appearance of eastward propagation of the SST and zonal wind anomalies from the Indian Ocean to the western Pacific. In the ensuing paragraphs we will investigate the specific air- 
SST (EQ)

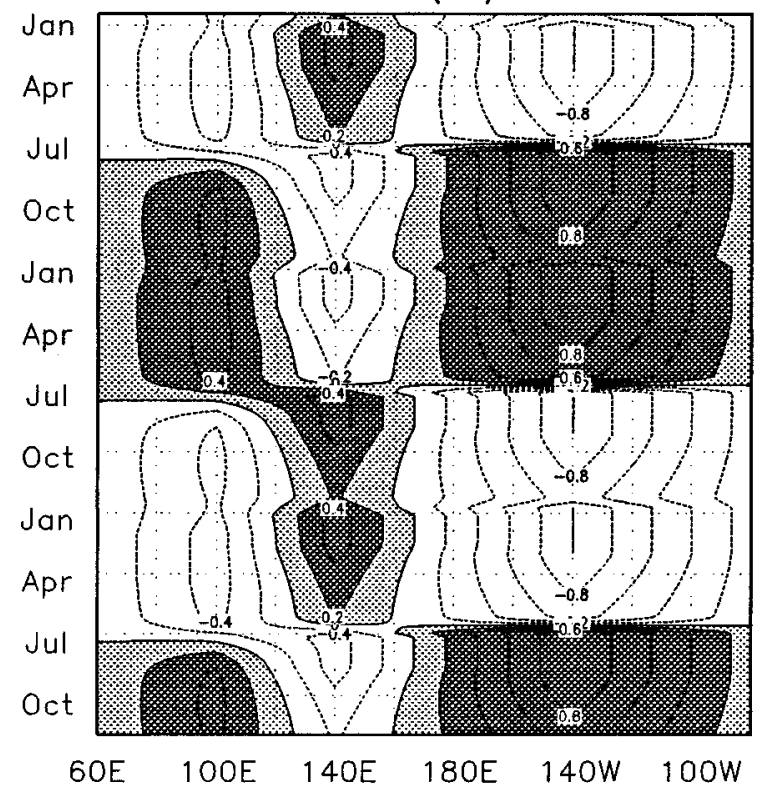

Zonal Wind (EQ)

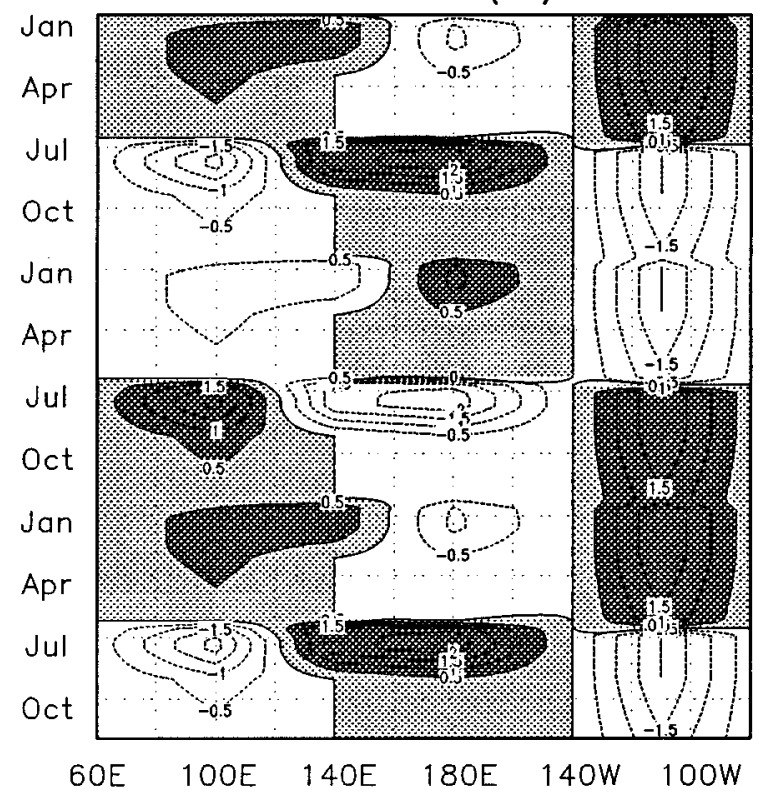

FIG. 7. Time evolution of the model SST (K, intervals 0.2) and zonal wind ( $\mathrm{m} \mathrm{s}^{-1}$, intervals 0.5$)$ anomalies, positive areas shaded. The eastern Pacific zonal wind is not a model variable. The wind anomalies east of $140^{\circ} \mathrm{W}$ are computed from zonal SST gradient anomalies due to $T_{E}$.

sea-land interactions that determine this simulated tropical TBO.

Figures $8 \mathrm{a}-\mathrm{c}$ show the time variations of individual terms that drive the anomalous SST in the Indian Ocean, eastern Pacific and western Pacific, respectively. In the Indian Ocean (Fig. 8a) the leading term is the evapo- ration feedback from the anomalous strength of the monsoon wind. It reverses sign sharply from warming into cooling as a strong Indian summer monsoon starts in June and overwhelms all other terms. The strong cooling lasts through summer and then decays rapidly when the monsoon season is over, keeping only $1 / 3$ of the amplitude in September. The decrease of cooling then slows down considerably through northern fall, reaching a minimum in December. Afterward, the onset of the Australian monsoon gives a modest boost to the cooling, so the cooling continues through the beginning of June. Without this boost, the trend in fall indicates that the evaporative cooling would be much diminished in northern spring.

In the eastern equatorial Pacific (Fig. 8b) the largest term is the thermocline variation, followed by the anomalous upwelling. They also switch sign sharply to cool the SST as the strong northern summer Asian monsoon starts. Because both terms are more efficient processes to cool the SST than evaporation, their magnitudes are considerably larger $\left(0.08 \mathrm{~K} \mathrm{day}^{-1}\right.$ and $0.028 \mathrm{~K} \mathrm{day}^{-1}$, respectively) than the evaporation cooling term in the Indian Ocean $\left(<0.015 \mathrm{~K} \mathrm{day}^{-1}\right)$. Therefore, even though they are counteracted by the damping effect of the mean upward advection of anomalous SST and the weaker evaporation due to the cooler sea surface, the cooling of the eastern Pacific is much more rapid and intense than the Indian Ocean. This stronger anomalous SST response in the eastern Pacific compared to the Indian Ocean can be seen clearly in Fig 6. The effect of the Australian monsoon to reinvigorate the cooling is more conspicuous than in the Indian Ocean, resulting in two significant peaks of SST rate changes each year in Fig. $8 b$.

In the western equatorial Pacific (Fig. 8c), the thermocline variation and the evaporation terms, which both peak at $0.014 \mathrm{~K} \mathrm{day}^{-1}$, are the leading terms. The former effect is due to the tilting of the thermocline, which has the opposite sign as in the eastern Pacific. The deepening of the thermocline in the western Pacific may increase local subsurface ocean temperatures (Meehl 1993), which may further reduce the effect of surface cooling due to wind-induced vertical mixing. On the other hand, the effect of anomalous upwelling has the same sign as in the eastern Pacific because both regions experience the same anomalous surface zonal wind associated with the planetary scale east-west circulation. However, the thermocline variation term dominates over the anomalous upwelling, so the time rate of change of SST in the western Pacific tends to be out of phase with that in the eastern Pacific and Indian Ocean. The evaporation term is also in phase with the thermocline variation term. During a strong Indian monsoon, the anomalous eastwest circulation produces anomalous surface easterly wind, which opposes the northern-summer mean westerly wind and reduces evaporation, leading to an increase in the western Pacific SST. The subsequent strong Australian monsoon induces anomalous westerlies in the 
(a)

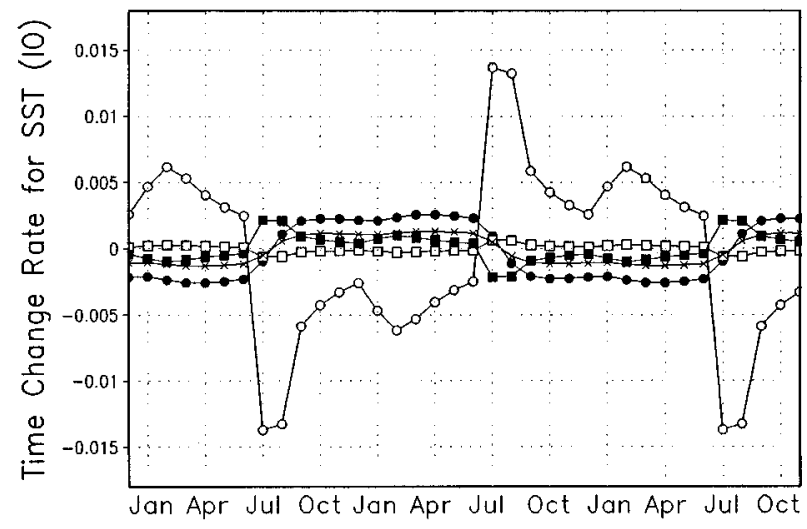

$\bigcirc-0-\lambda \Delta \bar{q}_{j} \frac{\bar{U}_{j} U_{j}}{V_{0}}$, evaporation due to anomalous wind

$\bullet-\lambda V_{n} \kappa T_{j}$, evaporation due to anomalous SST

$\square-\square-u \bar{T}_{j}^{(x)}-\bar{u} T_{j}^{(x)}$, anomalous zonal advection of temperature

- $-w \bar{T}_{j}^{(z)}$, temperature advection due to anomalous vertical current

$\mathbf{x} \longrightarrow \mathbf{x}-\frac{\bar{w}_{j}}{h} T_{j}$, temperature advection due to anomalous SST

$0 \_\frac{\bar{w}_{j}}{h} \gamma \eta_{j}$, temperature advection due to anomalous thermocline depth (b)

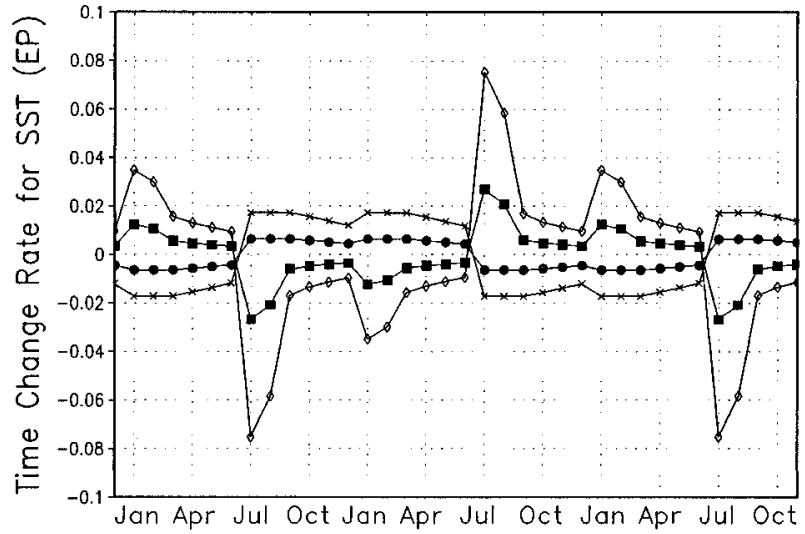

(c)

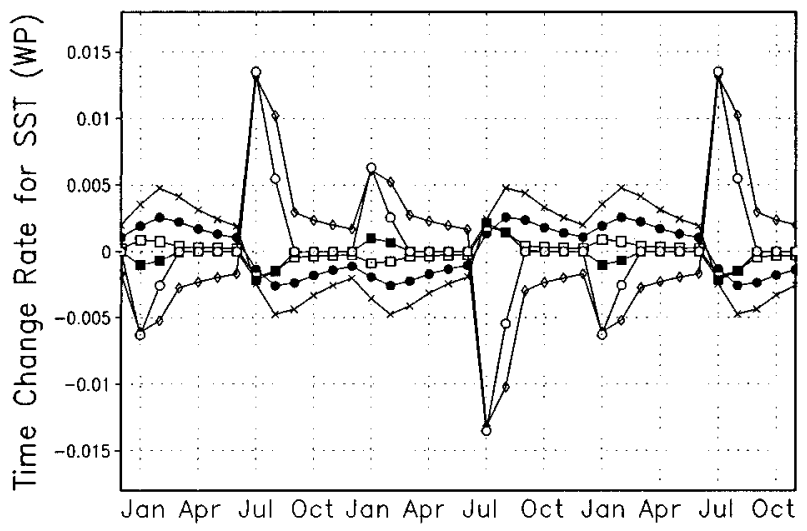

FIG. 8. Terms contributing to the time rate of change of SST in the (a) Indian Ocean, (b) eastern equatorial Pacific, and (c) western equatorial Pacific.

western Pacific. Since the mean zonal wind during northern winter is easterly, the evaporation is again reduced and the SST increases. The effect of the second SST change due to the Australian monsoon is also conspicuously manifested in the SST time series (Fig. 7), where two distinct maximums of the western Pacific SSTA are clearly indicated.

\section{Discussion}

In order to aid the discussion, a schematic diagram illustrating how the interactions between the monsoon, ocean, and atmosphere promote a biennial oscillation in the model is given in Fig. 9. In this figure the main cause and effects for the strong monsoon phase are given in the left-hand side, with the sequence of development driven by the northern summer events indicated by red solid thin and double arrows and that driven by the northern winter events indicated by black dashed arrows. The chain of events in the weak monsoon phase is only symbolically sketched on the right-hand side since the details are exactly mirror images of the lefthand side. The two phases are separated by a ribbon.
Figure 10, which is built from Figs. 5a-c and graphically summarizes all the important interactive processes, is presented as a companion diagram to Fig. 9 to help the discussion.

Since the starting point of an ideal TBO cycle is arbitrary, we will start from a warm SSTA condition in the Indian Ocean prior to the South Asian summer monsoon season, and follow the thin arrows in Fig. 9. The warm SSTA increase the local lower-tropospheric moisture through surface evaporation. As the South Asian summer monsoon develops, southerly winds to the south of the Indian subcontinent bring the excess water vapor into South Asia, which intensifies the convective rainfall and leads to a strong monsoon. The convective heating associated with the stronger monsoon on one hand induces a westerly wind anomaly over the Indian Ocean due to the enhanced low-level vorticity (indicated by a thin arrow), and on the other hand intensifies a planetary-scale east-west circulation leading to anomalous easterlies over the western and central Pacific (indicated by the solid double arrow). The westerly anomaly over the Indian Ocean decreases the local SST, primarily through the evaporation-wind feedback. This cooling 


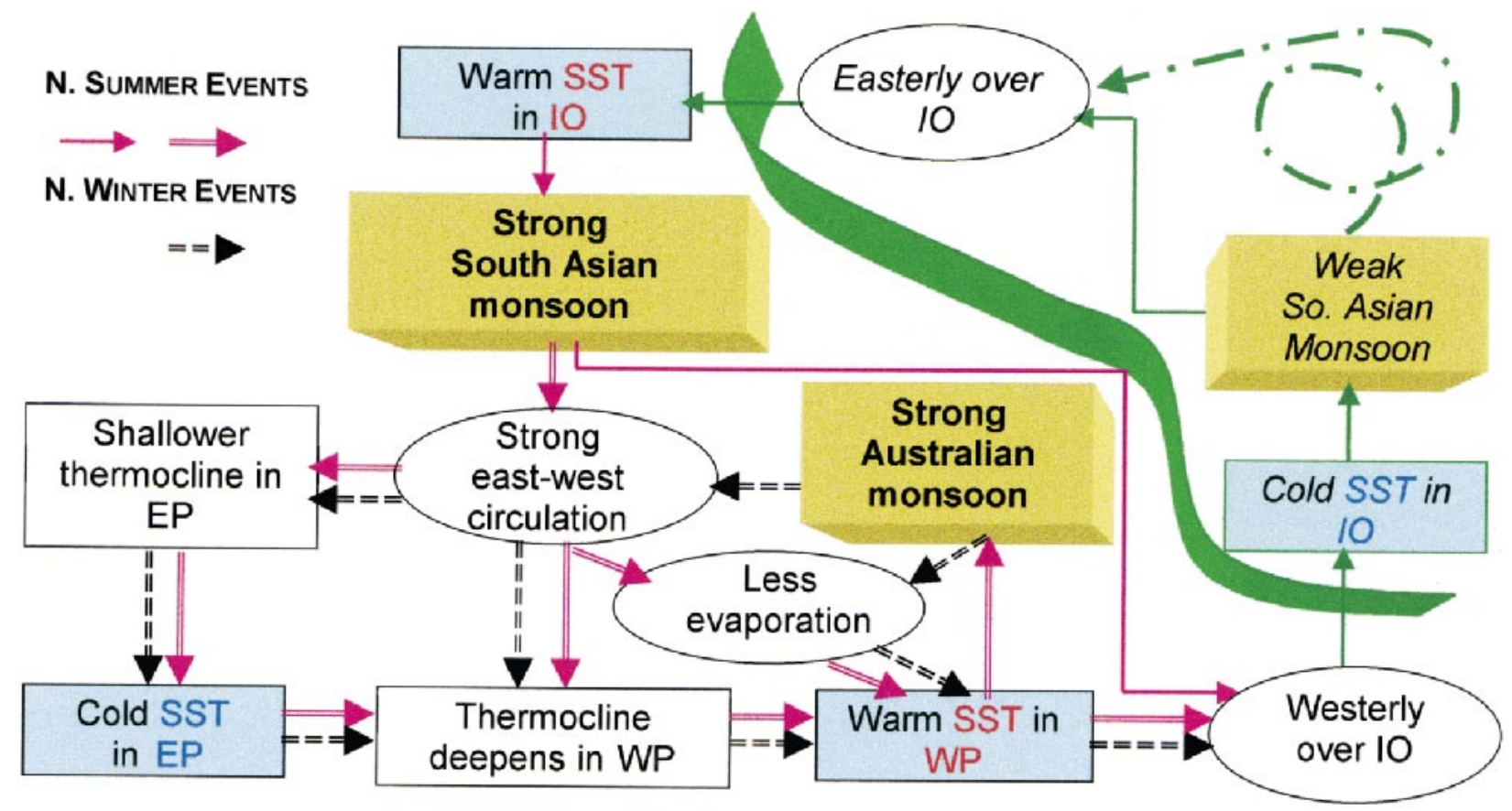

FIG. 9. Schematic diagram indicating the interactive processes leading to the TBO. Land and ocean regions are shaded. Nonshaded boxes indicate atmospheric (oval) and oceanic (rectangular) processes involved in the interactions. Northern summer-driven events follow red solid thin and double arrows, northern winter-driven events follow black-dashed double arrows. The strong monsoon phase starts with warm SST in the Indian Ocean leading to a strong South Asian monsoon in northern summer. In addition to a surface westerly anomaly over the Indian Ocean during northern summer (thin arrow) that cools the SST, complex interactive processes (double arrows, both summer and winter driven) involving both western and eastern equatorial Pacific and the Australian monsoon are required to reinvigorate this westerly anomaly until the next summer. These processes also lead to a strong northern winter monsoon that follows the strong summer monsoon. The reversed phase is sketched in the upper right side of the ribbon. See text for details.

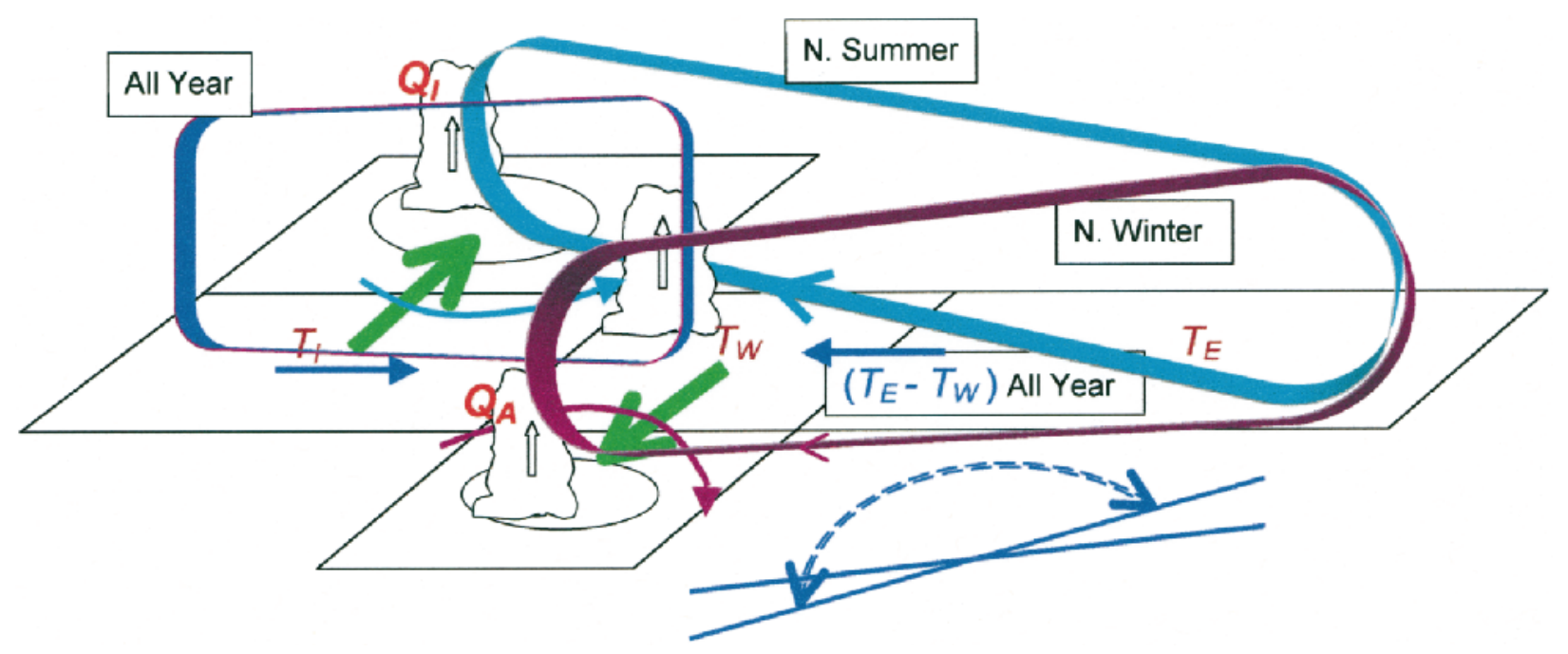

FIG. 10. Schematic diagram summarizing the important atmospheric, land, and ocean interactions. The northern summer processes are indicated by light blue, the northern winter processes by purple, and the year-round processes by dark blue. The primary mechanism in changing SST is through wind-evaporation for the Indian Ocean, thermocline tilting for the eastern equatorial Pacific, and both for the western equatorial Pacific. This diagram highlights the key roles played by the western equatorial Pacific both in allowing the northern summer monsoon to influence the northern winter monsoon, and in the maintenance of the Indian Ocean surface wind anomalies until the next monsoon by linking the feedback's of the Australian monsoon and the eastern equatorial Pacific to the Indian Ocean. 
will help the development of a weak phase of the South Asian summer monsoon if the cold SST can persist for nearly $1 \mathrm{yr}$.

We will now shift attention to the other branch of the summer-driven events (solid double arrows). In the western Pacific, the dominant term is the anomalous vertical temperature advection that is associated with the subsurface temperature or thermocline changes. Because the anomalous easterlies in the central Pacific deepen the ocean thermocline in the western Pacific, this term increases the SST in the western Pacific. Meanwhile, the anomalous easterlies in the western Pacific oppose the summer-mean westerlies resulting in reduced evaporation and additional warming. (The easterly anomaly also tends to cool the local SST through zonal advection and Ekman-induced upwelling, but both effects are small-the latter due to the weak mean vertical stratification in the western Pacific.) As a result, warm SSTA persist in the western Pacific through northern fall, which eventually leads to a stronger Australia monsoon in northern winter and the beginning of the winterdriven event sequence indicated by the dashed double arrows.

Whenever there is warming in the western Pacific, it strengthens the western branch of the Walker cell and thus a surface westerly anomaly over the Indian Ocean. Therefore, the westerly anomaly over the Indian Ocean is reinforced during northern fall (the solid double arrow). This helps the cold SST to persist through the succeeding seasons.

Meanwhile, the easterly anomaly in the central Pacific, through anomalous upwelling and shoaling of the thermocline, also cools the SST in the eastern Pacific. The east-west SST gradient further intensifies the anomalous easterlies over the central Pacific, reinforcing the tilting of the thermocline and the warming of the western Pacific SST.

The warm SSTA in the western Pacific is weakened in late northern fall by anomalous cold advection from the eastern Pacific. However, they are reinvigorated in the northern winter (Fig. 7) when the Australian monsoon becomes stronger. This is accomplished through two processes: the western Pacific westerly anomaly that weakens the winter-mean easterlies and reduces evaporation, and the central Pacific easterly anomaly (associated with the strengthened east-west circulation) via a change in the tilting of the thermocline.

Thus, the winter-driven events (indicated by the dashed double arrows) become the third mechanism (in addition to the local feedback and the summer-driven events) to keep the Indian Ocean's surface wind anomaly westerly and its SST cold, leading to a weaker Asian monsoon in the following summer. (The warm western Pacific SST further intensifies the eastern Walker cell and helps to keep the eastern Pacific cold.) This interactive system explains why the Indian Ocean SSTA can be kept from weakening rapidly.

The reversed cycle associated with a weak Asian monsoon is sketched to the upper-right of the ribbon in Fig. 9. The thin arrows that form a closed loop surrounding this ribbon represent the local wind-evaporation negative feedback theory of Meehl $(1987,1997)$ for the TBO of the South Asian monsoon. In order to explain the coherent temporal and spatial structure, the interactions between the monsoons, east-west circulation, and ocean thermocline variations, as represented by the double arrows (both solid and dashed) in the strong monsoon phase in Fig. 9, are required. These processes are responsible for an Australian monsoon whose TBO phase follows the South Asian monsoon, and for a sustainable SST anomaly in the Indian Ocean to cause a phase reversal of the TBO cycle 1 yr later.

\section{Concluding remarks}

Based on the results from a simple conceptual coupled atmosphere-ocean-land model, a mechanism for the tropical tropospheric biennial oscillation (TBO) is proposed. This simple model is designed to describe only the essential physics that is necessary and sufficient to reproduce the fundamental features of the observed tropical TBO. The key processes in this theoretical framework are the evaporation-wind feedback, the SST-monsoon feedback, and the feedback between the monsoon-driven east-west circulation and ocean thermocline variations. It is shown that the interactions of these processes can provide a plausible physical mechanism to develop the spatial and temporal structure of the observed TBO in the Tropics. Therefore, this theory explains two interesting questions of the TBO, namely, why a strong South Asian summer monsoon will lead to a strong Australian monsoon, and how the reversed SSTA following a South Asian summer monsoon can be sustained for several seasons to reverse the phase of the monsoon TBO in the next year.

In our model a Walker circulation between the western Pacific and the Indian Ocean is an essential component in the phase transition mechanism of the TBO. This Walker circulation allows the western Pacific-Maritime Continent region to play a crucial role in both the summer-to-winter monsoon transition and in sustaining the Indian Ocean SSTA after the monsoon. The region serves as a bridge in space and time, both in connecting the convection anomaly from the northern summer to the northern winter monsoon and in channeling the feedback of the northern winter monsoon (and that of the eastern Pacific if sufficiently strong) to the Indian Ocean (Figs. 9, 10). This role is due both to its central geographical location and its high mean SST, which is conductive to the active convection that drives the Walker cell over the Indian Ocean.

A question may be raised that the local feedback of SST on the South Asian monsoon is probably weak because the observed correlation of the Indian monsoon with Indian Ocean SST is only about $0.25-0.3$ (Fig. 2). However, we have conducted a preliminary study in 
which the data are bandpass filtered into TBO (1.5-3 yr) and ENSO (3-7 yr) windows. In the TBO window the correlation of spring Indian Ocean SST with the subsequent monsoon rainfall is $0.4-0.5$, while the correlation of spring east Pacific SST is much smaller. (The situation is reversed in the ENSO window.) Furthermore, the proposed TBO theory is based on processes within the Tropics, thus it excludes the possible feedback through tropical-midlatitude interactions. However, the possible effects of the forcing of the midlatitudes by tropical heating (Meehl 1994, 1997) and snow cover anomalies (e.g., Yanai and Tomita 1998) will not change the phase of the model biennial oscillation. This is because these effects would give rise to the same sign of response in the biennial cycle as that of the equatorial SST produced by the present model. Thus, the mechanisms that connect the TBO in the Indian summer monsoon to the subsequent Australian monsoon will still apply.

The TBO amplitude of Indian rainfall of $1.9 \mathrm{~mm}$ day $^{-1}$ in the present model is about $60 \%$ of the amplitude observed by Yasunari (1990). This underestimate implies that we have a smaller low-level moisture convergence anomaly. In our model the convective heating due to anomalous convergence of mean moisture is negligibly negative over the Indian Ocean when the SST is warm. But in the real atmosphere anomalous convergence into the monsoon region will develop following the anomalous heating. Thus this term would have been positive and nonnegligible, and contribute to an increase in the rainfall amplitude. We have also neglected the land temperature anomalies over South Asia associated with possible tropical-midlatitude interactions (Meehl 1994, 1997) These anomalies will affect the land-sea temperature contrast and may also increase the moisture supply. In future studies such processes can be added to the simple model.

Since the Indian Ocean in the model is represented by just one box, certain processes that could be important have been excluded. This includes the effect of the interannual variation of the zonal thermocline movement, and the cross-equatorial ocean heat transports in association with monsoon annual cycle. The latter makes an essential difference between Indian and $\mathrm{Pa}$ cific Oceans. These processes can also be added to the simple model in future studies.

A conspicuous difference between the model results (Fig. 7) and the observed lag correlation (Fig. 1) occurs in the eastern Pacific, where the monsoon-driven SSTA transition occurs in June rather than in northern spring. This is probably due to the exclusion of other types of air-sea interaction processes such as El Niño-Southern Oscillation (ENSO), which involves atmosphere-ocean interactions in the Pacific. Prior to middle 1970s El Niño and La Niña events frequently occurred in consecutive years and appeared to have a phase lock with the seasonal cycle. The El Niño's are strong events with SSTA several times higher than TBO (Ropelewski et al. 1992), so the forcing of an anomalous east-west circulation that may influence the Asian-Australian monsoon region in this case is more plausible. These El Niño-La Niña pairs may be manifested in the northern spring eastern Pacific SSTA transition in Fig. 1. On the other hand, after the late 1970s the ENSO seasonal phase lock with a spring transition is not obvious (Torrence and Webster 1998; Chang et al. 1999), and the eastern Pacific is dominated by lower-frequency variations. Our recent observational studies indicate that the SSTA there relative to the East Asian summer monsoon change sign mainly in northern fall instead of spring (Chang et al. 2000).

Our theory indicates that TBO is an inherent result of the interactions between northern summer and winter monsoon and the tropical Indian and Pacific Oceans. This TBO mechanism is different from ENSO. As is well known, ENSO involves ocean-atmosphere interaction processes mainly in the tropical Pacific. Its basic mechanism does not require a monsoon. On the other hand, the Asian-Australian monsoon is an essential part of the TBO. This consideration is an important difference from the view that ENSOs are extreme events of TBO (e.g., Meehl 1987, 1994). When both systems are present, the feedback between the monsoonal planetaryscale east-west circulation and ocean thermocline variations will impact directly the variation of ENSO with clear implications. A strong monsoon associated with TBO would produce an anomalous cooling tendency for the eastern/central equatorial Pacific SST. On the other hand, the possible influences of ENSO to the monsoon rainfall may be complex. The SSTA in the Indian Ocean and the eastern/central Pacific are generally in phase on interannual timescales. That is, during an eastern Pacific warm event the North Indian Ocean also tends to be warmer than average. By providing more moisture convergence into South Asia, this warm SST anomaly tends to favor a strong South Asian monsoon. However, the direct impacts of the circulation anomalies that are associated with a warm ENSO phase would produce a large-scale descent over the monsoon region. This anomalous descent would reduce the monsoon rainfall, either by reducing the intensity and life cycle of the monsoon disturbances, or by producing a displacement of the seasonal-mean rainfall pattern. The combination of these two opposite effects will determine the net effect of ENSO on the monsoon at a given time. Therefore, depending on the phase of the biennial mode at that time, the otherwise regular biennial cycle may be disturbed. The present theory predicts a robust TBO mode from northern summer through northern winter because of the interactions between the South Asian summer monsoon, the western equatorial Pacific, and the Australian monsoon regions. Therefore, the biennial cycle is most susceptible to be broken in northern spring, when SST in the Indian Ocean may be altered by various temporal and spatial-scale atmospheric (and ocean) motions. Among the possible interfering systems are the 
ENSO and the MJO. In a subsequent paper we will discuss the nonlinear interactions between ENSO and TBO that may disturb the regular cycles of both oscillations.

Acknowledgments. We wish to thank Dr. Jerry Meehl for motivating us to pursue this research, and Prof. Robert Haney for reading the manuscript. This work was supported in part by the National Science Foundation, under Grant ATM 9613746.

\section{APPENDIX}

\section{Derivation of SST Equations for the Equatorial Indian Ocean, Western Pacific, and Eastern Pacific}

The time change rate of SST anomaly in the equatorial Indian Ocean may in general have the following form:

$$
\begin{aligned}
\frac{\partial T_{I}}{\partial t}= & -u_{I} \bar{T}_{I}^{(x)}-\bar{u}_{I} T_{I}^{(x)}-v_{I} \bar{T}_{I}^{(y)}-\bar{v}_{I} T_{I}^{(y)}-w_{I} \bar{T}_{I}^{(z)} \\
& -\bar{w}_{I} T_{I}^{(z)}-\frac{Q_{I}^{(L H)}}{\rho c_{w} h},
\end{aligned}
$$

where $u, v$, and $w$ represent zonal, meridional, and vertical velocity in the ocean mixed layer, respectively; $T^{(x)}$, $T^{(y)}$, and $T^{(z)}$ denote the gradient of ocean temperature in $x, y$, and $z$ directions, respectively; a bar denotes basic-state quantity; subscript $I$ stands for the Indian Ocean; and $Q^{(L H)}$ represents latent heat flux anomaly at the ocean surface that may be linearly expressed as

$$
Q_{j}^{(L H)}=\rho_{a} c_{D} L \overline{\Delta q_{j}} \frac{\bar{U}_{j}}{V_{0}} U_{j}+\rho_{a} c_{D} L V_{0} \kappa T_{j},
$$

where $j=I, W$; or $E$, represent the Indian Ocean, western Pacific, and eastern Pacific, respectively.

Similarly, the time change rate for the equatorial western and eastern Pacific may be written as

$$
\begin{aligned}
\frac{\partial T_{W}}{\partial t}= & -u_{C} \bar{T}_{C}^{(x)}-\bar{u}_{C} T_{C}^{(x)}-v_{W} \bar{T}_{W}^{(y)}-\bar{v}_{W} T_{W}^{(y)} \\
& -w_{W} \bar{T}_{W}^{(z)}-\bar{w}_{W} T_{W}^{(z)}-\frac{Q_{W}^{(L H)}}{\rho c_{w} h} \\
\frac{\partial T_{E}}{\partial t}= & -u_{C} \bar{T}_{C}^{(x)}-\bar{u}_{C} T_{C}^{(x)}-v_{E} \bar{T}_{E}^{(y)}-\bar{v}_{E} T_{E}^{(y)} \\
& -w_{E} \bar{T}_{E}^{(z)}-\bar{w}_{E} T_{E}^{(z)}-\frac{Q_{E}^{(L H)}}{\rho c_{w} h} .
\end{aligned}
$$

Note that in Eqs. (A1), (A3), and (A4), we have neglected radiative and sensible heat fluxes at the ocean surface. Since the annual mean SSTs are approximately symmetric to the equator in the tropical Indian and western Pacific Oceans, we neglect the meridional temperature advection terms in (A1) and (A3). Since there is only one box over the Indian Ocean in the current frame- work, we do not take into account anomalous zonal temperature gradient so that $\bar{u}_{I} T_{I}^{(x)}=0$. This leads to the final form of Eq. (1).

Zonal temperature advection anomalies in the Pacific Ocean depend on basic-state zonal currents and temperature gradients in the central Pacific. Since the mean zonal current is always westward and because the zonal current anomaly on TBO scale in general only alters the strength, but not the sign, of the mean westward current, we drop the zonal temperature advection term in the $T_{E}$ equation. Furthermore, we assume that the TBO mode in the eastern Pacific is approximately symmetric to the equator. This leads to $V_{E}=T_{E}^{(y)}=0$. As discussed in Zebiak and Cane (1987), Neelin (1991), and Li (1997), we assume that subsurface ocean temperature anomalies in the Pacific depend on thermocline depth variations. Finally we drop the first term on the right-hand side of Eq. (A2) for the $T_{E}$ equation, simply because in the current framework the subsidence branch of the monsoon induced east-west circulation coincides with the $T_{E}$ box, so that anomalous zonal wind, $U_{E}$, is equal to zero.

\section{REFERENCES}

Barnett, T. P., L. Dumenil, U. Schlese, E. Roeckner, and M. Latif, 1989: The effect of Eurasian snow cover on regional and global climate variations. J. Atmos. Sci., 46, 661-685.

Bjerknes, J., 1969: Atmospheric teleconnections from the equatorial Pacific. Mon. Wea. Rev., 97, 163-172.

Cane, M. A., 1979: The response of an equatorial ocean to simple wind stress patterns. Part I: Model formulation and analytic results. J. Mar. Res., 37, 233-252.

Chang, C.-P., Y. Zhang, and T. Li, 2000: Interannual and interdecadal variations of the East Asian summer monsoon and tropical Pacific SSTs. Part I: Roles of the subtropical ridge. J Climate, in press.

Clarke, A. J., X. Liu, and S. V. Gorder, 1998: Dynamics of the biennial oscillation in the equatorial Indian and far western Pacific Oceans. J. Climate, 11, 987-1001.

Kiladis, G. N., and H. van Loon, 1988: The Southern Oscillation. Part VII: Meteorological anomalies over the Indian and Pacific sectors associated with the extremes of the oscillation. Mon. Wea. Rev., 116, 120-136.

Kraus, E. B., and J. S. Turner, 1967: A one dimensional model of the seasonal thermocline. Part II: The general theory and its consequences. Tellus, 19, 98-105.

Krishnamurti, T. N., 1971: Tropical east-west circulation during the northern summer. J. Atmos. Sci., 28, 1342-1347.

— west circulations during the northern winter. J. Atmos. Sci., 30, 780-787.

Kuo, H.-L., 1974: Further studies of the parameterization of the influence of cumulus convection on large-scale flow. J. Atmos. Sci., 31, 1231-1240.

Lau, K. M., and S. Yang, 1996: The Asian monsoon and predictability of the tropical ocean-atmosphere system. Quart. J. Roy. Meteor. Soc., 122, 945-957.

Li, T., 1997: Phase transition of the El Niño-Southern Oscillation: A stationary SST mode. J. Atmos. Sci., 54, 2872-2887.

_ model for monthly mean surface winds and precipitation over the tropical Pacific. J. Atmos. Sci., 51, 1372-1385.

Lindzen, R. S., and S. Nigam, 1987: On the role of sea surface 
temperature gradients in forcing low level winds and convergence in the Tropics. J. Atmos. Sci., 44, 2240-2458.

Matsumoto, Y., and T. Yamagata, 1991: On the origin of a model ENSO in the western Pacific. J. Meteor. Soc. Japan, 69, 197207.

Meehl, G. A., 1987: The annual cycle and interannual variability in the tropical Pacific and Indian Ocean region. Mon. Wea. Rev., $115,27-50$.

_ 1993: Coupled ocean-atmosphere-land processes and South Asian monsoon variability. Science, 265, 263-267.

_ 1994: Influence of the land surface in the Asian summer monsoon: External conditions versus internal feedback. J. Climate, 7, 1033-1049.

— 1997: The South Asian monsoon and the tropospheric biennial oscillation (TBO). J. Climate, 10, 1921-1943.

Mooley, D. A,. and B. Parthasarathy, 1984: Fluctuations in All-India summer monsoon rainfall during 1871-1978. Climatic Change, 6, 287-301.

Neelin, J. D., 1991: The slow sea surface temperature mode and the fast-wave limit: Analytic theory for tropical interannual oscillation and experiments in a hybrid coupled model. J. Atmos. Sci., 48, 584-606.

Nicholls, N., 1978: Air-sea interaction and the quasi-biennial oscillation. Mon. Wea. Rev., 106, 1505-1508.

_ 1979: A simple air-sea interaction model. Quart. J. Roy. Meteor. Soc., 105, 93-105.

— 1984: The Southern Oscillation and Indonesian sea-surface temperature. Mon. Wea. Rev., 112, 424-432.

Philander, S. G. H., 1990: El Niño, La Niña, and the Southern Oscillation. Academic Press, 293 pp.

Rasmusson, E. M., and T. H. Carpenter, 1982: Variations in tropical sea surface temperature and surface wind fields associated with the Southern Ocillation/El Niño. Mon. Wea. Rev., 110, 354-384.

Reed, R., W. J. Cambell, L. A. Rasmusson, and D. G. Rogers, 1961: Evidence of a downward propagating annual wind reversal in the equatorial stratosphere. J. Geophys. Res., 66, 813-818.
Ropelewski, C. F., M. S. Halpert, and X. Wang, 1992: Observed tropospheric biennial variability and its relationship to the Southern Oscillation. J. Climate, 5, 594-614.

Shen, S., and K. M. Lau, 1995: Biennial oscillation associated with the East Asian monsoon and tropical sea surface temperatures. J. Meteor. Soc. Japan, 73, 105-124.

Tian, S. F., and T. Yasunari, 1992: Time and space structure of interannual variation in summer rainfall over China. J. Meteor. Soc. Japan, 70, 585-596.

Tomita, T., and T. Yasunari, 1996: Role of the northeast winter monsoon on the biennial oscillation of the ENSO/monsoon system. J. Meteor. Soc. Japan, 74, 399-413.

Torrence, C., and P. J. Webster, 1998. The annual cycle of persistence in the El Niño/Southern Oscillation. Quart. J. Roy. Meteor. Soc., 124, 1985-2004.

Wang, B., and T. Li, 1993: A simple tropical atmospheric model of relevance to short-term climate variations. J. Atmos. Sci., 50, 260-284.

Webster, P. J., and S. Yang, 1992: Monsoon and ENSO: Selectively interactive systems. Quart. J. Roy. Meteor. Soc., 118, 877-926.

_ , V. O. Magana, T. N. Palmer, J. Shukla, R. A. Tomas, M. Yanai, and T. Yasunari, 1998: Monsoons: Processes, predictability, and the prospects for prediction. J. Geophys. Res., 103 (C7), 14 45114510.

Yanai, M., and T. Tomita, 1998: Seasonal and interannual variability of atmospheric heat sources and moisture sinks as determined from NCEP-NCAR reanalysis. J. Climate, 11, 463-482.

Yasunari, T., 1990: Impact of Indian monsoon on the coupled atmosphere ocean system in the tropical Pacific. Meteor. Atmos. Phys., 44, 29-41.

- 1991: The monsoon year-A new concept of the climate year in the Tropics. Bull. Amer. Meteor. Soc., 72, 1331-1338.

_ iability of Indonesian monsoon rainfall. Tropical Rainfall Measurements, J. S. Theon and N. Fugono, Eds., Deepak, 113-122.

Zebiak, S. E., and M. A. Cane, 1987: A model ENSO. Mon. Wea. Rev., 115, 2262-2278. 